\title{
Social Networks in Transnational and Virtual Communities
}

\author{
Nathan Vivian and Fay Sudweeks \\ Murdoch University, Perth, Australia
}

\section{n.vivian@murdoch.edu.au sudweeks@murdoch.edu.au}

\begin{abstract}
There has been extensive research on social networks but little is known about why some communities survive and some disintegrate. This paper provides a framework to explain similarities in many types of communities. In particular, a comparison of transnational communities and virtual communities highlights the efficacy of the framework in explaining how strong relationships within communities are dependent on social formation factors such as a sense of identity, social structures and social capital.
\end{abstract}

Keywords : Social networks, transnational communities, virtual communities, social formation, social spaces.

\section{Introduction}

There is a vast amount of literature preaching the benefits of online, transnational and virtual communities. The development of simple social networks has explained why some of these communities are able to grow despite adverse conditions but the literature does not explain how these communities are created and maintained. The importance of social networks should not be underestimated. Portes (1995) explains, "Migration is a process that both depends on and creates social networks".

The benefits of social networks do not cease with migration. From a virtual community perspective, Kimball \& Rheingold (2000) explain that "the online social network provided a venue for storytelling, showcasing, projects and best practices that could be leveraged to create new knowledge resources". This paper will briefly discuss issues associated with social networks and then propose a framework for creating and maintaining social networks, regardless of size and the communication medium.

\section{Social Networks}

Individuals create interpersonal bonds with others within their social network, however these bonds are "in some unspecified way causally connected with the actions of these persons with the social institutions of their society" (Barnes, 1954). It is these interwoven patterns and matrices that can facilitate the success or failure of societies and organizations that depend on these networks (Freeman, 2000). Hence the creation of these networks are pertinent to the analysis of community development, whether virtual or transnational.

Vertovec (2001) highlighted the benefits of using social networks, by explaining how interpersonal rela-

Material published as part of these proceedings, either on-line or in print, is copyrighted by Informing Science. Permission to make digital or paper copy of part or all of these works for personal or classroom use is granted without fee provided that the copies are not made or distributed for profit or commercial advantage AND that copies 1) bear this notice in full and 2) give the full citation on the first page. It is permissible to abstract these works so long as credit is given. To copy in all other cases or to republish or to post on a server or to redistribute to lists requires specific permission from the publisher at Publisher@InformingScience.org tions cut across boundaries such as neighbourhood, workplace, kinship or class and could be abstracted on an individual basis. Furthermore, Nohria \& Eccles (1992) indicate that social ties are not fixed, as the networks are constantly being socially constructed and altered by their members. 
Figure 1: Proposed framework for the creation and maintenance of social networks

Encourages the notion of belonging, especially in respect to a community

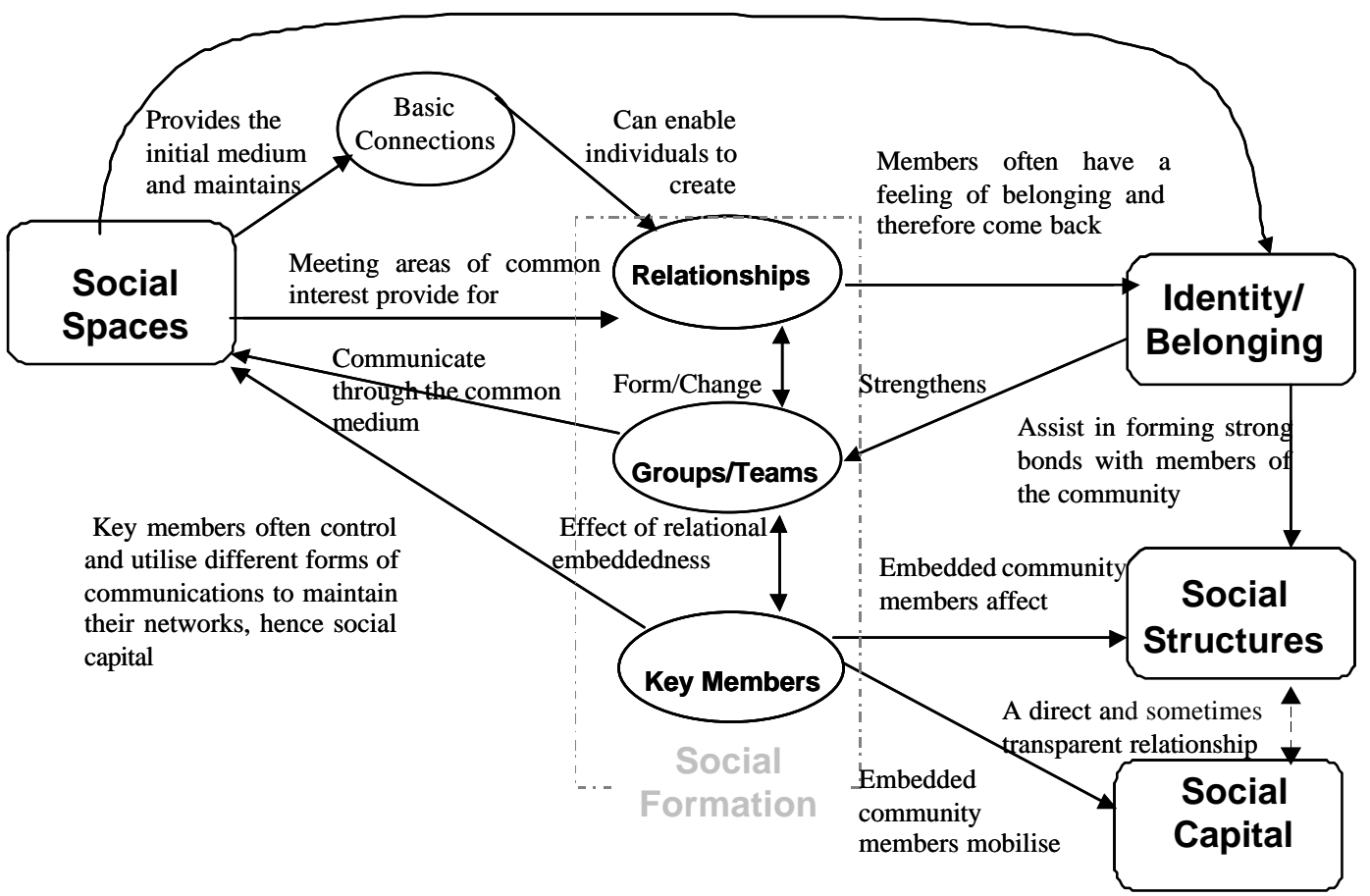

Sociologists, until the 1950s, anticipated the loss of community and disconnected, weakly supportive relationships arising due to "rapid modernisation" (Wellman \& Gulia, 1999). Yet the realisation of the Internet provided for community creation well beyond expectation, where individuals are members of virtual communities with ties comparable to their offline neighbourhoods. Although these ties are maintained through social networks, the facilitation of the networks is provided by social spaces.

In this paper, we develop a conceptual framework (Figure 1) that could allow for flexibility in design, yet still be applicable in different communities.

\section{Social Spaces}

In the proposed framework, the concept of social spaces has been fused from sociological grounding, but extends to information technology. For instance, Sassen (2000) defined social spaces to explain transnationalism: "a space that is both place-centered, in that it is embedded in particular and strategic locations, and it is transterritorial because it connects sites that are not geographically proximate yet are intensely connected to each other". Comparably, Kimball \& Rheingold (2000) write from an IT perspective: "Shared social space actually creates the identity of the group, ... the campus, ... the town square, ... these are the contexts that help us define who we are as members of a particular group or community."

The framework depicted in Figure 1 melds the se two concepts. We could say that social spaces and places are where individuals first meet and create their contacts. Or, in some environments, social spaces are new areas where people can meet, communicate with others and assimilate. Social spaces provide the initial medium to form and maintain basic connections, which in turn enable individuals to create relationships. 


\section{Social Formation}

Social movements have, for some time, influenced communities. There are many different definitions of social movements, depending on which aspect of community or social structure is being looked at. We use Tarrow's (1998) general definition of social movements, which involves "collective changes, based on common purposes and social solidarities, in sustained interaction with elites, opponents and authorities". Social struc ture is greatly affected by how social formations within communities interact with each other.

From a rudimentary perspective, we could identify relationships between individuals or between groups. These relationships are mostly dynamic, typically short-term, and strengthen a sense of identity and belonging in groups and teams. Such groups are made up of individuals with many relationships, often in different social arenas, yet these groups are often identifiable in any community. The key members are those who are stakeholders within their community. The roles of key players affect social structures and social capital, and their influence is through the use of communication and social spaces to maintain their networks.

The notion of embeddedness was first raised by Granovetter (1985) and is a term used to explain that "all social action and outcomes are affected by actors' dyadic (pairwise) relations and by the structure of the overall network of relationships". These members of the community can be embedded in two different ways, according to Portes (1995): relational embeddedness would involve key members' personal relations with one another, "including norms, sanctions, expectations and reciprocity"; structural embeddedness refers to social relationships and the different associated scales. In other words, members are embedded in the community in two ways: the first refers to how they relate to each other, and the second is how the social relationships affect social structures.

Therefore, social formation and social structures are dependent on the relationships of the me mbers within their community, as illustrated in Figure 1.

\section{Social Capital}

The concept of social capital is often misunderstood. A number of definitions for social capital exist, however Annen (Forthcoming) definition shall be used: "Social capital is defined as a player's reputation for being cooperative within a social network. A social network is a set of players and a pattern of exchange of information and/or goods among these players." Similarly Portes (1995) highlighted that the resources of any player is not the social capital, rather it is the individual's ability to mobilize that capital on demand.

Social capital is the key to control in a community, as the members of that community (with highly mobile social capital) have the greatest control over social structures. This control is not obtained overnight, but developed and maintained over time through regular communication, participation in events and membership to associations (Annen, Forthcoming; Vertovec, 2001). It is these activities, combined with analysis, which helps describe why some individual groups and organizations perform better than others (Burt, 2000). And it is Blanchard and Horan (1998) who, drawing on Putnam, explain that participation is not capital building, as reciprocation is required. In Figure 1, these elements of social capital are represented as links from key members.

\section{Applying the Framework}

Now that we have identified the main characteristics of social networks, we apply the framework in Figure 1 to describe transnational migration and virtual communities. 


\section{Transnational Migration}

If we look at transnational migration, we notice that it is not only individual people who migrate but, to a large extent, their networks migrate also. As Vertovec (2001) points out, "For migrants, social networks are crucial for finding jobs and accommodation, circulating goods and services, as well as psychological support and continuous social and economic information". This network building is supported by Portes (1995) who proposes that migration in itself "can be conceptualized as a process of network building, which depends on and, in turn, reinforces social relationships across space".

The framework in Figure 1 has been designed to explain how social networks are created, and to illustrate this we will use the following hypothetical case of an Italian family migrating to Australia.

An Italian family migrates to Australia with very little knowledge and no contacts. They search for other people with whom they can assimilate. The family decides to have dinner at an Italian restaurant [social space] in order to feel a little more at home. Here they meet other Italians who have recently experienced the same migration [basic connections]. Some have been in Australia a little longer and occupy a large table with their friends. The Italian family takes contact details of people they meet.

A few weeks later, the family decides to return to the same restaurant because they enjoyed the homely feeling of the restaurant [identity]. While at the restaurant, the family meets one of the families they had met previously, and discover that their sons enjoy soccer. The sons decide to join a team together [relationships]. The next week both families meet at the local soccer club [social space] where they meet others who have the same interests. The two families form more relationships based on their sons playing soccer, and enjoy drinks together after the games [social groups].

At the end of the soccer season, the two families decide they really enjoyed each other's company and begin to participate in other activities in the community, by joining an Italian Club. Other members of the soccer group see less of each other, but still remain in contact [relationships] and see each other at the restaurant. The two fathers begin to grow large networks through the Italian Club, and are now seen as prominent figures [key members] in the community [embeddedness].

A new member of the Italian Club buys a new house and needs help with laying tiles on the floor. The two fathers phone their friends who happily help to tile the floor [social capital]. The two fathers regularly attend meetings and functions outside the Italian Club, and maintain their contacts. By now, the Italian migrant family identifies with the club and feel a great sense of belonging and therefore thrive in their new community.

Although this is a hypothetical case, many of these events were common in the Southern European migrant boom in Australia during the 1940s and 1950s, and it highlights the common applicability of the framework in regards to the establishment of new communities, especially those transnational in nature. The question now is: Does this framework work for other examples such as online communities?

\section{Virtual Communities}

Communities existing online, using mediated communication only, are known as virtual communities (also referred to as online/networked/distributed communities). Social relationships are no less valid than those that occur in 'real' life, as ties to the community are also intermittent, specialized, and varying in strength (Wellman \& Gulia, 1999), regardless of medium.

Members of a virtual community bring their offline values into their discussions and interactions (Wellman \& Gulia, 1999), therefore intertwining both social lives together. "If the net were solely a means of information exchange, then virtual communities played out over the net would mostly contain only narrow, specialised relationships" (Wellman \& Gulia, 1999).

Similarly, Miller (2000) believes that for many individuals' 'online' life should not be separated from their 'offline' life and is critical of the common view that the Internet is a placeless place, because many of their informants gave little distinction between e-commerce and other commerce or between play- 
ground chat and ICQ chat, further highlighting how virtual communities are sociologically, for all intents and purposes, the same as their brick and mortar counterparts.

Apart from benefits arising from CSCW, Kimball and Rheingold (2000) outline the economic benefits to online social networks, as does Annen (Forthcoming) who links financial benefits with high levels of social capital. An individual's reputation within any given social network is considered an asset (Annen, Forthcoming). How the individual's networks and knowledge is maintained can equate to being a key member. How do they become key members and why do some stay? Another hypothetical case illustrates how the framework applies to virtual communities in organisations.

A medium sized organisation has a number of branches that are located in the same city but too far for board members to commute to all branches regularly. The organisation decides to create an online social network in which personnel can connect and discuss issues [social spaces]. While online, a board member meets individuals working in different branches [basic connections] and colleagues who are working on a related project [relationships].

During a discussion with the board member, an employee who is normally reserved in face-toface discussions describes a solution that seems innovative and viable. He is praised for his efforts and during the next face-to-face meeting, he is recognised and feels more important in the social structure [identity/belonging].

After three months of using the online social network, the board member has established a number of successful teams within different branches. When she needs to procure some goods in a limited time, she is able to call on her colleagues with whom she has strong ties, and through the network of teams in different branches, is able to secure the goods in record time [key members mobilising social capital].

Another job opportunity comes up, but the board member does not want to leave her current job as she feels she belongs and is now considered a key member of the online community, regardless of her position.

Again, this is a simplistic example but it can be seen that the framework in Figure 1 explains social formations through the experiences of the board member.

It should be noted that in both the virtual community and transnational migration cases, community members experienced a feeling of belonging and well-being. Furthermore, the hypothetical cases illustrate how social networks do not depend on one relationship, or on the social spaces in which people meet. Rather, the process of creating relationships and embedding oneself into the social structure is pertinent to the success of social ne tworks.

\section{Overcoming Boundaries}

The framework depicted in Figure 1 allows for transnational borders to be crossed. From a trans national perspective, social spaces could be two different countries (Portes, 1996). As explained by Vertovec (2001): 'transnational circuits' are the perpetual back and forth border crossing movements among migrants. This is identified in the framework by the interaction of key members with social spaces.

Similarly virtual communities are needed in many situations because "people who are geographically separated or on the road need a way of maintaining contact with their peers, whether they are in their specialty or a project team or in the company as a whole" (Kimball \& Rheingold, 2000). A major benefit of connecting members from different [geographical] areas means there is less reinventing the wheel. Also communication can take place in environments where face-to-face communication is not important or deemed necessary. 


\section{Conclusion}

There is evidence that similar social networks occur in many situations. We have identified the importance of social networks in both transnational and virtual communities. We have also described the benefits that arise from applying the framework depicted in Figure 1 to different situations. However, the framework can be applied to many other social network-building activities, such as the educational environment, in the workplace, on the sports field, or in the bridge club.

Further research needs to be conducted in order to assess the feasibility of the framework to a range of real cases rather than the two hypothetical cases presented here.

\section{References}

Annen, K. (Forthcoming). Social capital, inclusive networks, and economic performance. Journal of Economic Behavior \& Organization.

Barnes, J. (1954). Class and committees in a Norwegian island parish. Human Relations, 7, 39-58.

Blanchard, A., \& Horan, T. (1998). Virtual communities as social capital. Social Science Computer Review, 16, $293-307$.

Burt, R. (2000). The network structure of social capital. Research in Organizational Behaviour, 22(22), 345 -423.

Freeman, L. C. (2000). Visualising social networks. Journal of Social Structure, 1(1).

Granovetter, M. (1985). Economic action and social structure: The problem of embeddedness. American Journal of Sociology, 94, 481-510.

Kimball, L., \& Rheingold, H. (2000). How online social networks benefits organizations. Retrieved March 6, 2003 from www.rheingold.com/Associates/onlinenetworks.html.

Miller, D., \& Slater, D. (2000). The Internet: An ethnographic approach. Oxford: Berg.

Nohria, N., \& Eccles, R. G. (1992). Networks and organizations: Structure, form, and action. Boston: Harvard Business School Press.

Portes, A. (1995). The economic sociology of immigration. In A. Portes (Ed.), Economic Sociology and the Sociology of Immigration: A conceptual Overview (pp. 1-41). New York: Russell Sage Foundation.

Portes, A. (1996). Global villagers: The rise of transnational communities. The American Prospect(25), 74-77.

Sassen, S. (2000). New frontiers facing urban sociology at the millennium. British Journal of Sociology, $15(1), 143-159$.

Tarrow, S. (1998). Power in movement: Social movements and contentious politics. Cambridge: Cambridge University Press.

Vertovec, S. (2001, June 30-July 1). Transnational social formations towards conceptual cross fertilization. Paper presented at the Transnational Migration: Comparative Perspectives, Princeton University.

Wellman, B., \& Gulia, M. (1999). Net surfers don't ride alone: Virtual communities as communities. In B. Wellman (Ed.), Networks in the Global Village (pp. 331-367). Boulder, CO: Westview Press.

\section{Biographies}

Nathan Vivian is an Associate Lecturer in Information Systems at Murdoch University, He has a BCom (Management and Telecommunications Management), and a BSc (Business Information Systems and Information Systems Development) from Murdoch University. Currently he is a Masters in Knowledge Management candidate at Murdoch University, with research interests in virtual communities, virtual organisations, organisational behaviour, human resource economics and data communications.

Fay Sudweeks is a Senior Lecturer in Information Systems at Murdoch University. She has Bachelor (Psychology and Sociology) and Master (Cognitive Science) degrees from the Unive rsity of New South Wales. Her current research interests are social, cultural and economic aspects of computer-mediated communication and CSCW, group dynamics, e-commerce and e-learning. She has published 6 edited books, 8 edited proceedings, and more than 50 papers in journals, books and conference proceedings. 
She is on the editorial review board of the International Journal of e-Learning, Journal of ComputerMediated Communication, Journal of Electronic Commerce in Organizations, and Journal of Electronic Commerce Research. She has co-chaired three international and interdisciplinary conferences on $\mathrm{Cul}$ tural Attitudes towards Technology and Communication (CATaC). Fay has given invited talks in numerous countries including the USA, South Africa, Russia, Germany, Israel, and Sweden. 